\title{
Presentación de juego de platinas y mesa de mediciones para cirugía de modelos en cirugía ortognática
}

\author{
Introducing plates kit and measuaring platform for \\ model surgery in orthognatic surgery
}

\author{
Juan José Trujillo Fandiño,* Víctor Manuel González Olmedo, \\ Miguel Barrientos Velázquez ${ }^{\S}$
}

\section{RESUMEN}

La cirugía ortognática es una de las ramas de la cirugía maxilofacial que requiere de un análisis integral del paciente, así como una planeación cuidadosa mediante estudios cefalométricos, análisis clínico y cirugía de modelos para alcanzar un diagnóstico y plan de tratamiento adecuado para cada paciente. La cirugía de modelos es un paso crítico en la planeación de este acto quirúrgico. La precisión con la que se lleve a cabo la cirugía de modelos determinará el éxito que se obtenga durante el procedimiento quirúrgico, esto con la finalidad de transferir las medidas exactas de los movimientos planeados durante la predicción quirúrgica. Se presenta la técnica empleada para la cirugía de modelos en el Hospital Juárez de México, así como la mesa para obtener las medidas de dicho procedimiento.

Palabras clave: Cirugía ortognática, cirugía de modelos, planificación de tratamiento.

\section{ABSTRACT}

Orthognatic surgery is one of the branches of maxillofacial surgery that requires a comprehensive analysis of the patient, also a meticulous cephalometric planning, facial clinical analysis and model studying, to reach an accurate diagnosis and treatment for the patient. The orthognatic model surgery planning it's a critical step before the procedure in the surgery room. The precision obtained during the model surgery, will determine the outcome achieved during the orthognatic surgery procedure, this with the finality of transfer the exact measurements obtained during the surgical prediction. The author introduces an orthognatic surgery model planning used in the Hospital Juarez de Mexico, and the surgical table were the measurements are obtained.

Keywords: Orthognatic surgery, model surgery, treatment planning.

* Médico adscrito de Cirugía Maxilofacial Hospital Juárez de México.

‡ Práctica privada Hospital Ángeles Lomas, Ciudad de México.

\& Práctica privada Tuxtla Gutiérrez, Chiapas.

Correspondencia:

Dr. Juan José Trujillo Fandiño

Hospital Juárez de México,

Avenida Instituto Politécnico Nacional Núm. 5160

Col. Magdalena de las Salinas, 07760 ,

Alcaldía Gustavo A Madero, Ciudad de México, México.

Tel: 55864979.

E-mail: jjtrujillof@gmail.com 


\section{INTRODUCCIÓN}

La cirugía ortognática involucra reubicar los huesos del esqueleto facial, requiere de movimientos maxilares tridimensionales complejos para mejorar la estética facial y función del paciente. Esto se debe planear cuidadosamente por medio del trazado de predicción quirúrgica y de la realización de la cirugía de modelos, con el fin de que esto sea realizado en el paciente dentro del quirófano.

La cirugía de modelos de acuerdo con Epker, Stella y Fisch ${ }^{1}$ o cirugía de modelos definitiva de acuerdo con Erickson, Bell y Goldsmit ${ }^{2}$ es el medio por el cual se anticipan las osteotomías a realizar, la cantidad de hueso a remover y la oclusión final deseada durante el acto quirúrgico. La reposición precisa de los huesos deberá cumplir con las demandas funcionales y estéticas de cada paciente, para corregir sus anomalías dentoesqueletales.

Los pioneros en cirugía ortognática (Hullihen 1849; Angle 1903; Blair 1907) ${ }^{3}$ confiaban básicamente en la apariencia clínica y quirúrgica. Kostecka (1931) ${ }^{3}$ utilizaba únicamente modelos no articulados para evaluar la oclusión pre- y postquirúrgica.

La cirugía de modelos convencional se lleva a cabo mediante la toma de impresiones, obtención de modelos en yeso, la transferencia del arco facial con la posición del maxilar al articulador semiajustable la mayoría de las veces o con articulador ajustable ocasioalmente, y finalmente con la fabricación de las férulas quirúrgicas. Actualmente se realiza esto mismo por medio de una tomografía, un software para la planeación quirúrgica y la impresión final de las férulas.

Uno de los pasos críticos, donde la precisión es de gran importancia y que consumen tiempo durante la cirugía de modelos, es la reubicación de los maxilares con base en las medidas obtenidas en la predicción quirúrgica en el articulador. Esto se ha llevado a cabo mediante la interposición de una base de cera, la cual es calentada hasta llevar a la nueva posición el maxilar, otros utilizan yeso, el cual se desgasta de igual forma hasta la posición deseada. Se han descrito técnicas mediante la aplicación de imanes a los modelos de estudio, lo que facilita la movilidad y la orientación final del modelo mediante elásticos de interposicion, ${ }^{4}$ así como juguetes tipo Lego, los cuales han adaptado como material para facilitar el procedimiento mediante movimientos geométricos. ${ }^{5}$

En la actualidad existe el empleo de estudios en tercera dimensión, los cuales mediante programas realizan estudios cefalométricos, análisis facial y predicciones quirúrgicas donde se pueden confeccionar férulas o dispositivos que ayudan a posicionar el segmento óseo en el lugar deseado, han relegado un poco la cirugía de modelos convencionales en países desarrollados debido a la aplicación cada día más frecuente de estos programas. ${ }^{6-8}$

Sin embargo, a falta de acceso a este recurso tecnológico, la cirugía de modelos convencional debe ser aplicada y dominada perfectamente. Se presenta la técnica de cirugía de modelos empleada en el Hospital Juárez de México utilizando platinas elaboradas a base de Trovicel, facilitando la manipulación de los modelos, logrando realizar fácil, rápido y con exactitud los movimientos planeados en la predicción quirúrgica.

\section{Composición y dimensiones de platinas y mesa de mediciones}

Las platinas utilizadas para la cirugía de modelos están elaboradas a base de una estructura de policloruro de vinilo (PVC) espumoso (Trovicel), la cual tiene las propiedades de volverse una estructura espumosa uniforme que permite una mínima absorción de agua, fácil de cortar, pegar, termo formar, ligera y con cierta flexibilidad. Lo cual lo hace un material ideal de fácil manejo durante las maniobras en la cirugía de modelos.

Las platinas son elaboradas de forma rectangular, respetando la filosofía de la geometría que facilita su manipulación. Éstas son elaboradas con un perímetro general de $70 \times 55 \mathrm{~mm}$ en tres diferentes grosores, de 6, 3 y $1 \mathrm{~mm}$ (Figura 1). Estos grosores permiten aumentar o disminuir la cantidad de platinas intermedias según el movimiento requerido.

La mesa de mediciones se encuentra elaborada del mismo material que las platinas, conservando las propiedades ya mencionadas. Ésta se encuentra diseñada con un perímetro de $185 \mathrm{~mm}$ por 105 $\mathrm{mm}$ con una altura de $22 \mathrm{~mm}$. La gran ventaja de esta mesa es su bajo peso y su costo económico (Figura 2).

\section{Cirugía de modelos}

\section{Montaje y colocación de platinas intermedias}

Inicialmente se realiza un registro de mordida y posteriormente la toma del arco facial de manera convencional.

La fijación de orquilla del arco facial se realiza utilizando material de polivinilsiloxano, el cual brinda 
una impresión fiel de las superficies dentales, y por otro lado la estabilidad y rigidez de éste transfiere adecuadamente la posición del maxilar.

De acuerdo con los movimientos maxilares y a la magnitud de éstos, se calcula la cantidad necesaria de platinas para tener el suficiente espacio para realizar
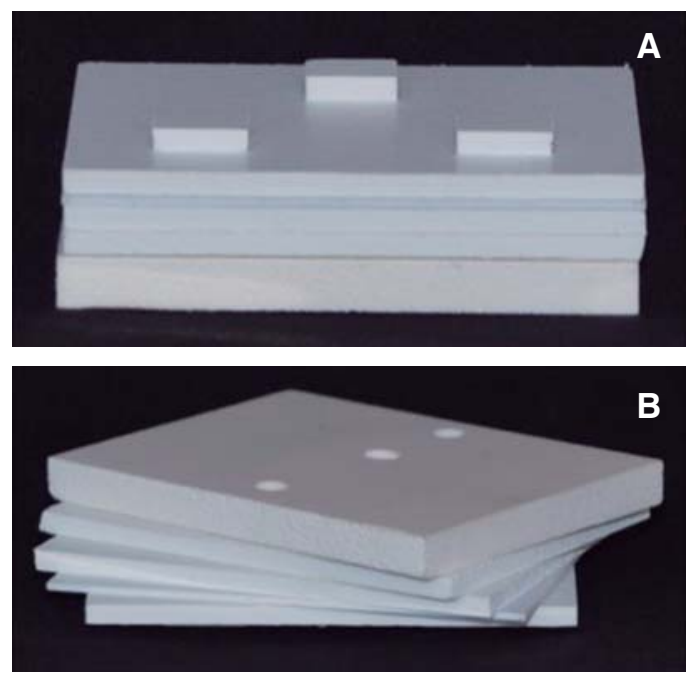

Figura 1: Diferentes grosores de platinas. A) Se muestra platina unida a modelo de estudio la cual presenta 3 retenciones cuadradas. B) Platina base la cual presenta 3 orificios los cuales se engarzan al articulador. los movimientos en el articulador, lo cual se calcula en el trazado de predicción quirúrgica. Las platinas se colocan una encima de la otra coincidiendo sus bordes y se pegan solamente por las equinas con pegamento a base de cianocrilato en pequeña cantidad. Fijas las platinas al articulador, el articulado de los modelos se realiza de manera convencional con yeso (Figura 3).

En esta instancia, es el momento ideal para trazar las líneas de referencia. Estas líneas de referencia se trazan desde la platina base hasta el modelo ya
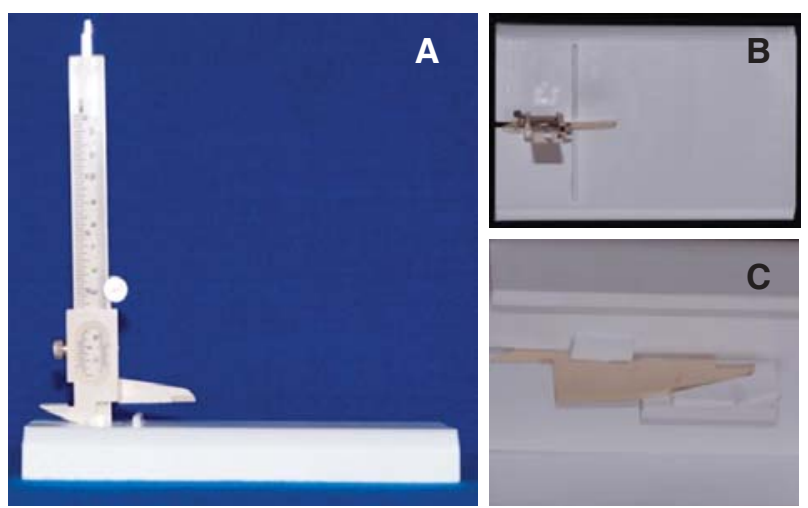

Figura 2: Mesa de mediciones. A) Vista lateral de mesa con vernier engarzado. B) Vista superior de mesa. C) Acercamiento a la parte inferior de la unión del vernier a mesa y su retención.
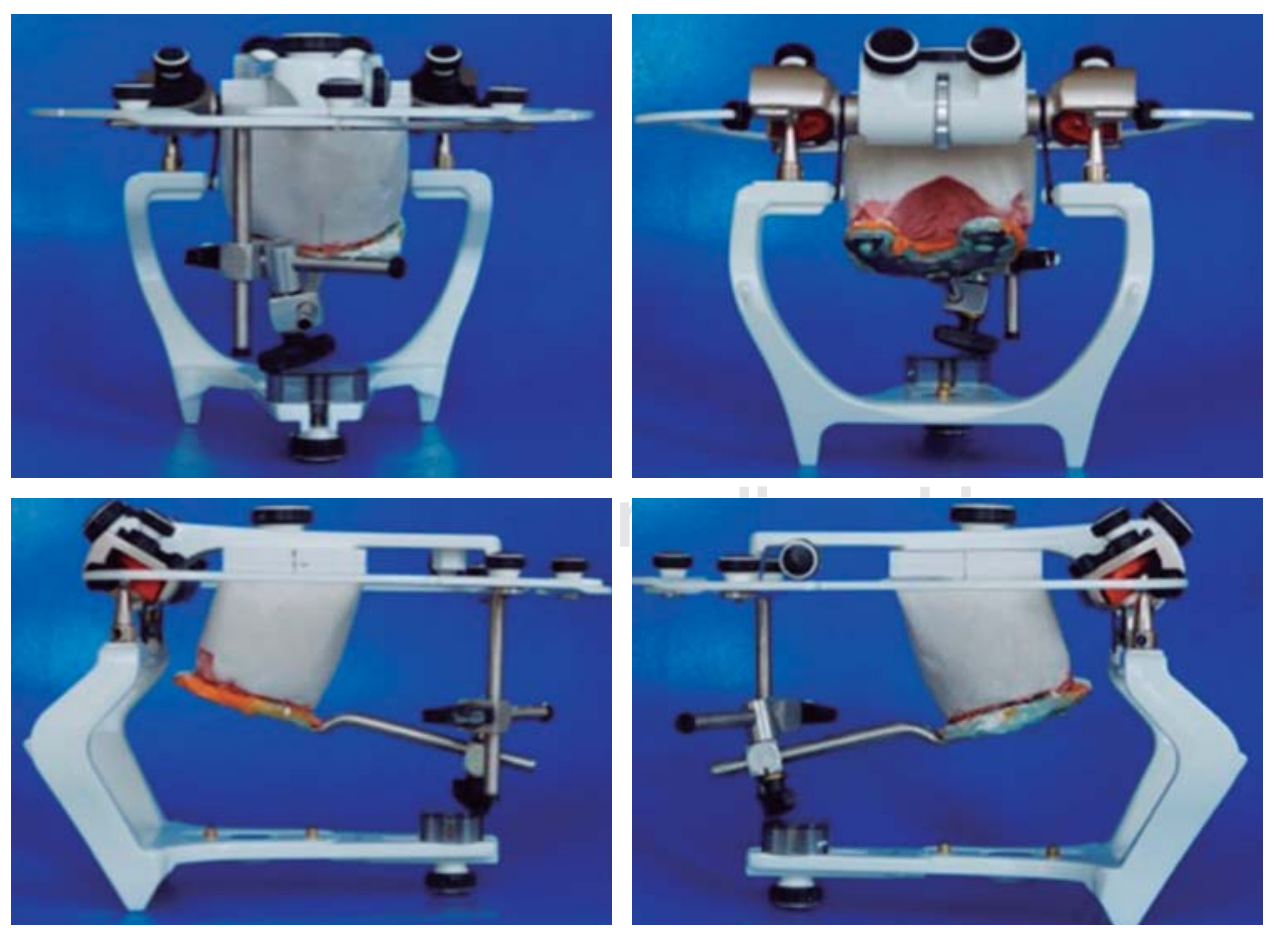

Figura 3:

Montaje de modelos y colocación de platinas. 
Figura 4:

Trazado de líneas de referencia en platinas y modelo de estudio.
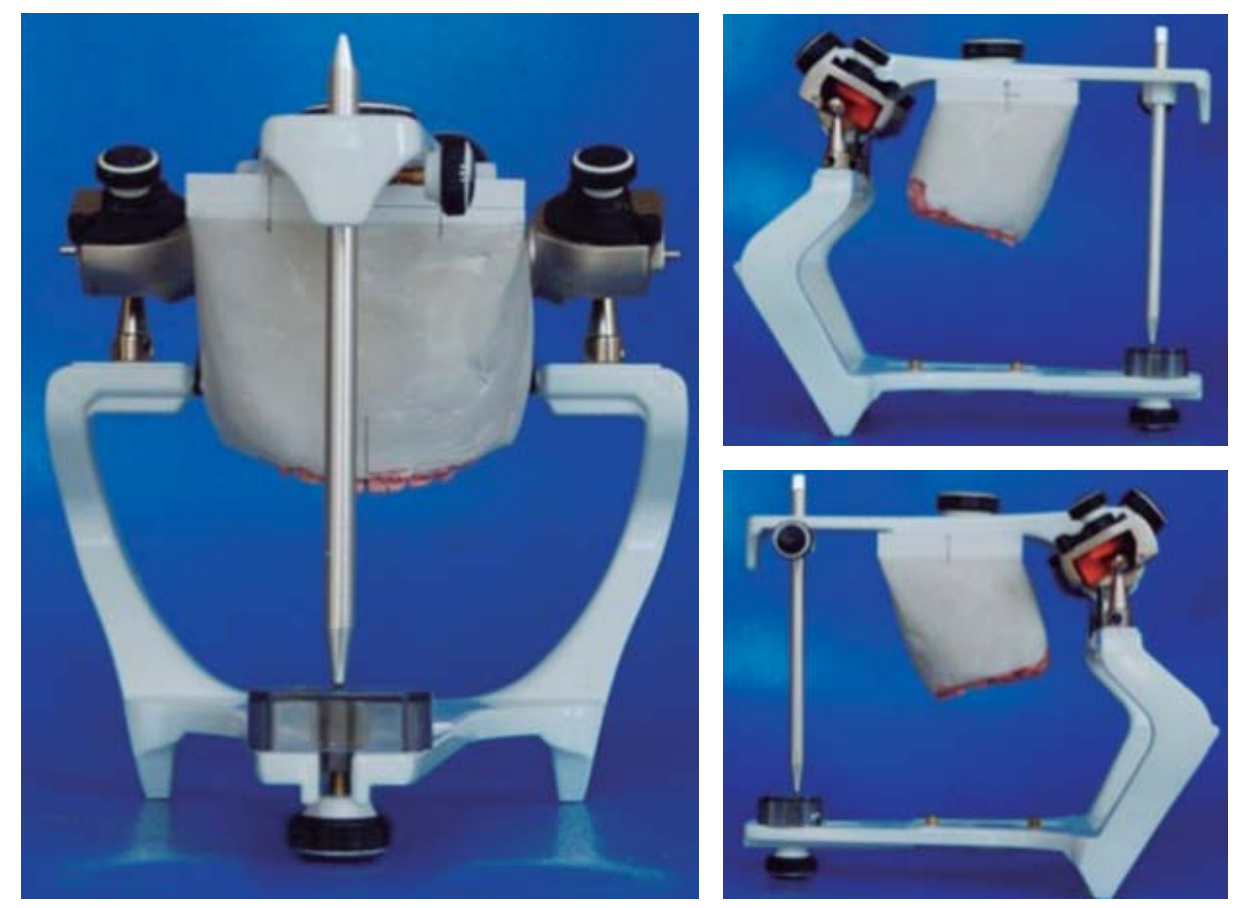
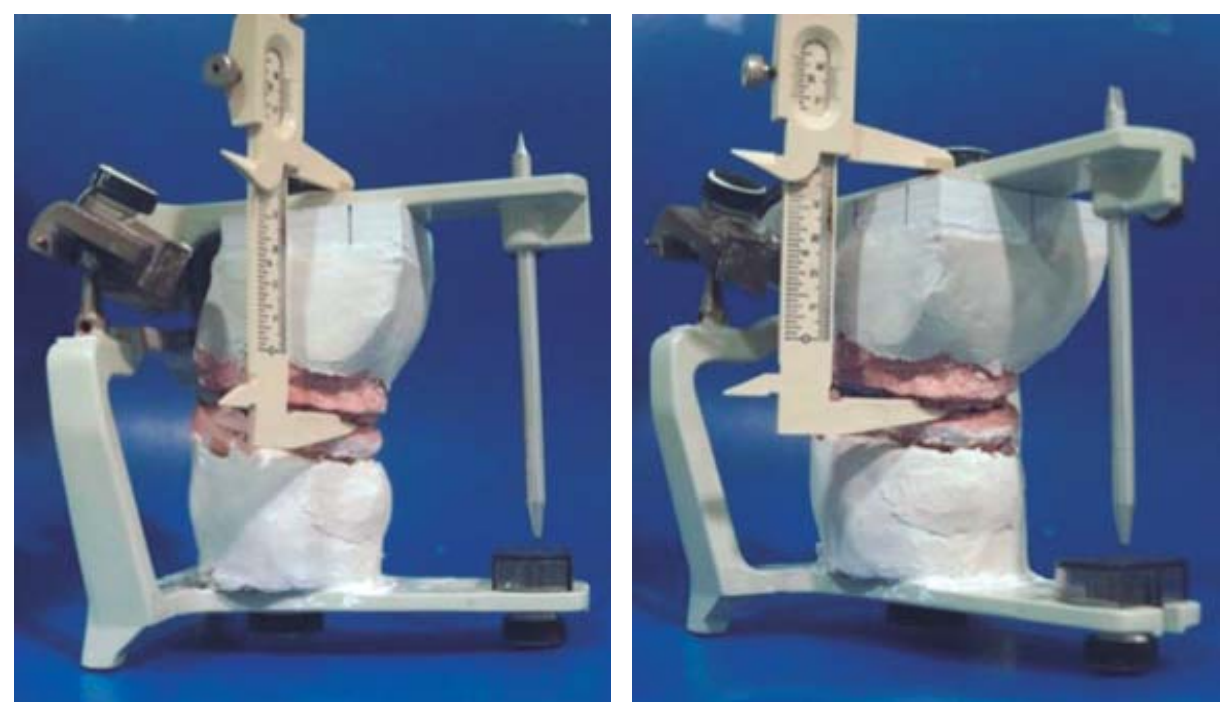

Figura 5:

Toma de medidas del brazo del articulador al borde incisal de los centrales, caninos y cúspide mesiovestibular del molar. montado. Las líneas de referencia en este caso se trazan por la parte frontal en la línea media y dos líneas de manera lateral equidistantes. Por las partes laterales se trazan en la parte media de la platina y en la parte posterior dos líneas más equidistantes en el centro de cada proceso alveolar derecho e izquierdo. Estas líneas servirán de referencia para observar el movimiento realizado (Figura 4).

Las líneas de referencia se desplazarán según el movimiento requerido.
El modelo antagonista es montado mediante la colocación del registro de mordida y agregando yeso para su fijación.

\section{Toma de mediciones en dos tiempos}

Inicialmente, la toma de medidas se lleva acabo con el modelo montado al articulador, éstas se obtienen mediante el uso de un vernier, tomando en cuenta la referencia del brazo del articulador al borde 
incisal de los centrales superiores, borde incisal del canino y cúspide mesiovestibular del primer molar, éstas se llevan a cabo de manera bilateral y de forma perpendicular al brazo del articulador (Figura 5). Para medir la proyección anteroposterior se toma en cuenta la referencia entre el vástago del articulador a la cara vestibular de ambos centrales superiores, también medida con la guía metálica del vernier.

Las medidas obtenidas se registran en un formato de recolección de datos (Figura 6). El formato del maxilar articulado es representado por imágenes para facilitar el entendimiento de las medidas a registrar.

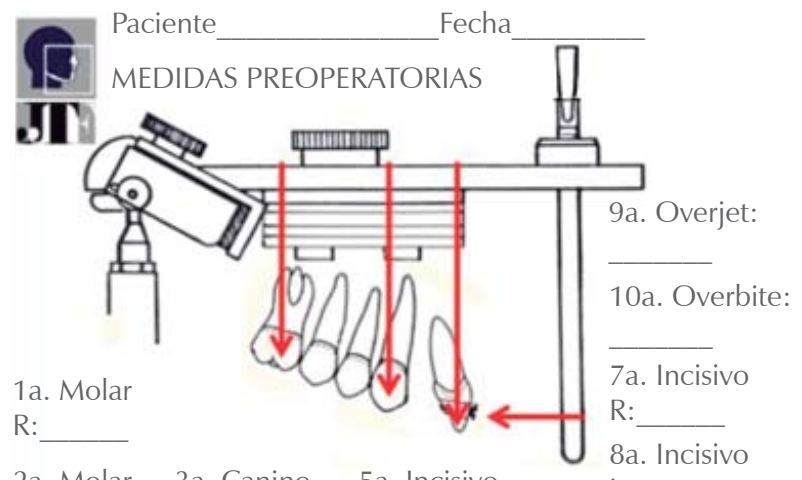

2a. Molar $\mathrm{L}:$ $\mathrm{R}$ : R: 6a. Incisivo L:

4a. Canino L:

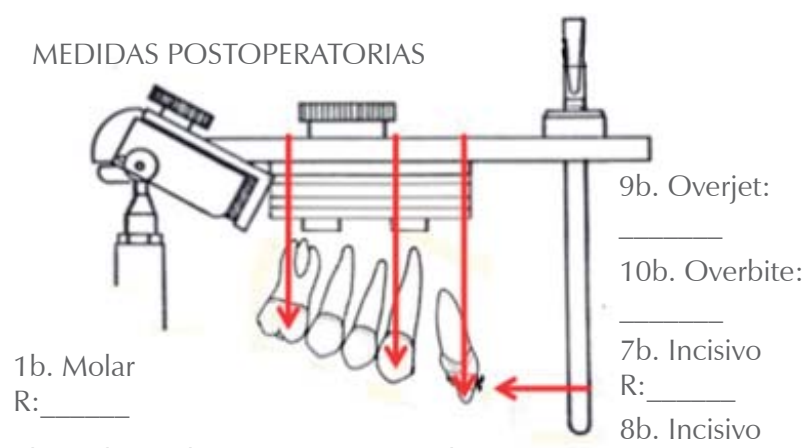

2b. Molar 3b. Canino $\mathrm{L}:$ R: R: $\mathrm{L}$ : 4b. Canino L:

Figura 6: Formato de registro de mediciones en articulador. Muestra con las flechas rojas las diferentes medidas que se deberán registrar en el pre- y post- de la cirugía de modelos.
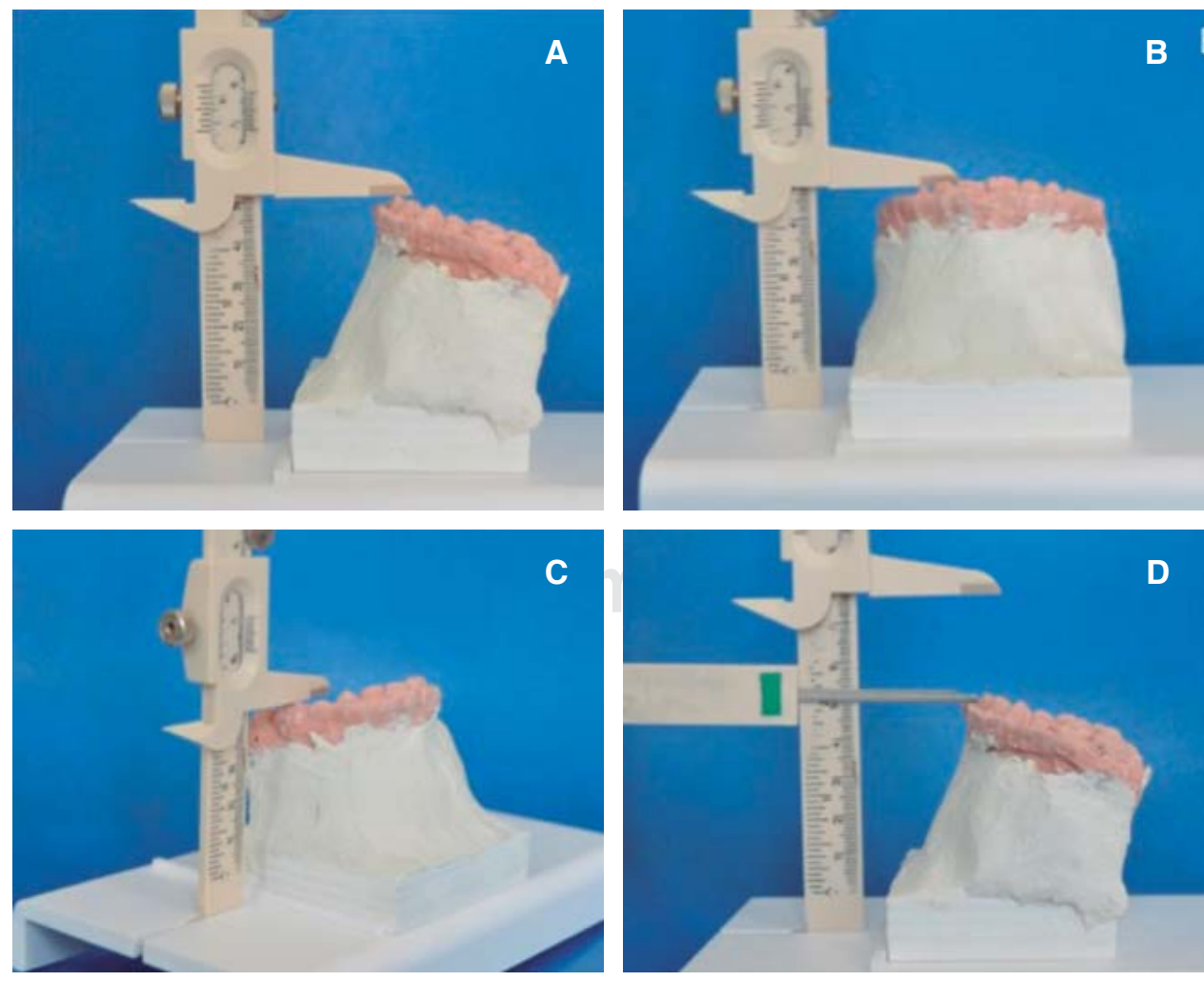

Figura 7:

Toma de medidas en mesa de mediciones. A) Medida al borde incisal. B) Medida a borde incisal al canino. C) Medida a cúspide mesiovestibular del primer molar. D) Medida anteroposterior para registrar proyección a la cara vestibular del incisivo. 
Esto permite corroborar los movimientos planeados en la predicción quirúrgica y en la cirugía de modelos. Asimismo, permite recordar la cantidad de milímetros a modificar durante el procedimiento quirúrgico.

Una vez obtenidas las medidas en el articulador, se procede a desmontar el modelo superior con las platinas y se traslada a la mesa de mediciones, donde se realiza la toma de las mediciones previas a los movimientos. Éstas se llevan a cabo mediante el vernier engarzado a la mesa de mediciones tomando como referencia el borde incisal de los centrales, caninos y cúspide mesiovestibular del primer molar. La medición de posición anteroposterior se lleva a cabo mediante el empleo de la guía metálica de un segundo vernier contrapuesto al de la mesa de mediciones (Figura 7).

Estas medidas se registran de igual forma en el formato de la mesa de mediciones, el cual muestra mediante imágenes las medidas a tomar. Éstas se encuentran representadas por campos con el órgano dental a medirse, número arábigo para mantener un orden, la letra $R$ para el lado derecho y $L$ para el lado izquierdo (Figura 8).

Las medidas se deberán obtener de ambos lados de la arcada y se registrarán previa y posteriormente a la cirugía de modelos, lo que permite corroborar el movimiento realizado.

\section{Cirugía de modelos}

Ya registradas las medidas iniciales y calculados los movimientos y medidas que deben tener posterior a realizar los movimientos durante la cirugía de modelos, se procede a despegar las platinas del modelo (Figura 9). En este paso se retiran o se colocan platinas intermedias según sean requeridas, de acuerdo con la cantidad de milímetros a impactar o descender el maxilar. Cabe recordar que los diferentes grosores de las platinas facilitan este paso y lo vuelve más estable y predecible.

Para iniciar el movimiento, se procede a colocar plastilina entre la platina fija al modelo y las platinas intermedias remanentes y la platina que va fija al articulador. Los movimientos se realizan presionando el modelo para lograr las medidas de los movimientos planeados en la predicción quirúrgica (Figura 10). Estos movimientos se calculan agregando o restando milímetros a las medidas obtenidas en la mesa de mediciones, corroborando las veces que sean necesarias las medidas mediante el vernier. Se toman en cuenta las referencias del borde incisal del incisivo, canino y cúspide mesiovestibular del primer molar, así como la proyección a la cara vestibular de los incisivos, las cuales se llevan a cabo de igual forma de manera bilateralmente. Una vez que se logran obtener los movimientos deseados, se procede a fijar la platina del modelo a las platinas intermedias o a la platina base que va fija al articulador, lo cual se logra recortando y pegando fragmentos de las platinas intermedias. Estos segmentos se colocan entre la interface de las platinas, se pegan con cianocrilato para fijarlas y mantener firmemente y de manera estable el movimiento realizado, para poder llevarlas nuevamente al articulador para corroborar el movimiento realizado. Cabe mencionar que la discrepancia que existe entre las líneas de referencia trazadas en las platinas representa el movimiento realizado (Figura 11).

Se toman las medidas logradas con el movimiento realizado y se comparan con las anotadas en el formato, las cuales deben coincidir. Lo que corrobora que el movimiento realizado fue el movimiento planeado.

Estos movimientos se pueden corroborar de manera adicional con el trazado de predicción quirúrgica; ya que los movimientos de las platinas en el articulador se realizan también en la hoja de la predicción quirúrgica. Por lo que se puede colocar el modelo con las platinas sobre el trazo de predicción y verificar si los movimientos realizados son idénticos a los obtenidos en el trazado de predicción quirúrgica (Figura 12).

Verificados los movimientos, se puede elaborar la férula intermedia para el procedimiento quirúrgico. La férula final se elabora mediante la articulación de nuevos modelos de estudio con base en la oclusión final deseada en un articulador de bisagra o semiajustable.

\section{DISCUSIÓN}

El advenimiento de la cirugía de modelos virtuales a través de tomografías que tienen la capacidad de realizar diseños faciales en computadora, predicciones quirúrgicas, así como la fabricación de férulas quirúrgicas, ya se encuentran actualmente disponibles en el mercado. Si bien es cierto que es un método novedoso, no se encuentra al alcance de todos los cirujanos debido a su alto costo y al poco entrenamiento de los cirujanos. ${ }^{5,9} \mathrm{El}$ procedimiento virtual aún no está libre de error y su entendimiento requiere saber y comprender el manejo del método convencional 
Paciente: Fecha:

MEDIDAS PREOPERATORIAS

1a. Incisivo

R:

2a. Incisivo

$\mathrm{L}$ :

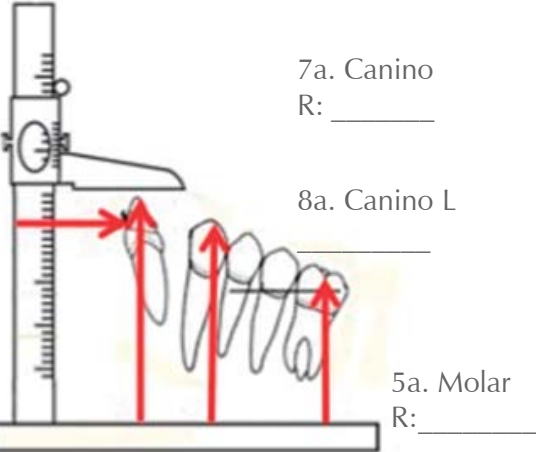

3a. Incisivo R:

6a. Molar

4a. Incisivo L:
MEDIDAS POSTOPERATORIAS

1b. Incisivo

$\mathrm{R}$ :

2b. Incisivo $\mathrm{L}$ :

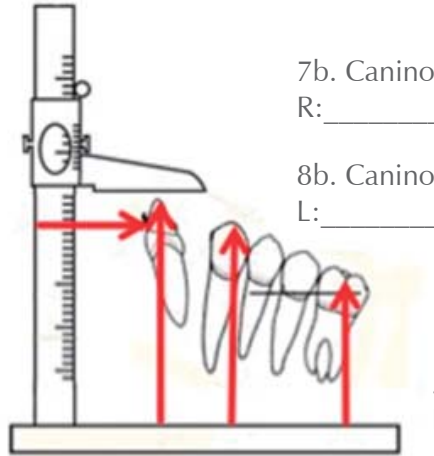

b. Molar R:

3b. Incisivo R:

6b. Molar $\mathrm{L}$ :

4b. Incisivo L:

Figura 8: Formato de registro en mesa de mediciones. Las flechas rojas muestran las medidas que se deberán registrar previamente y posterior a la cirugía de modelos.

Figura 9:

Se mantiene la platina del modelo de estudio al despegar las platinas intermedias de la ya mencionada. Se retiran o se agregan platinas intermedias según sea necesario.
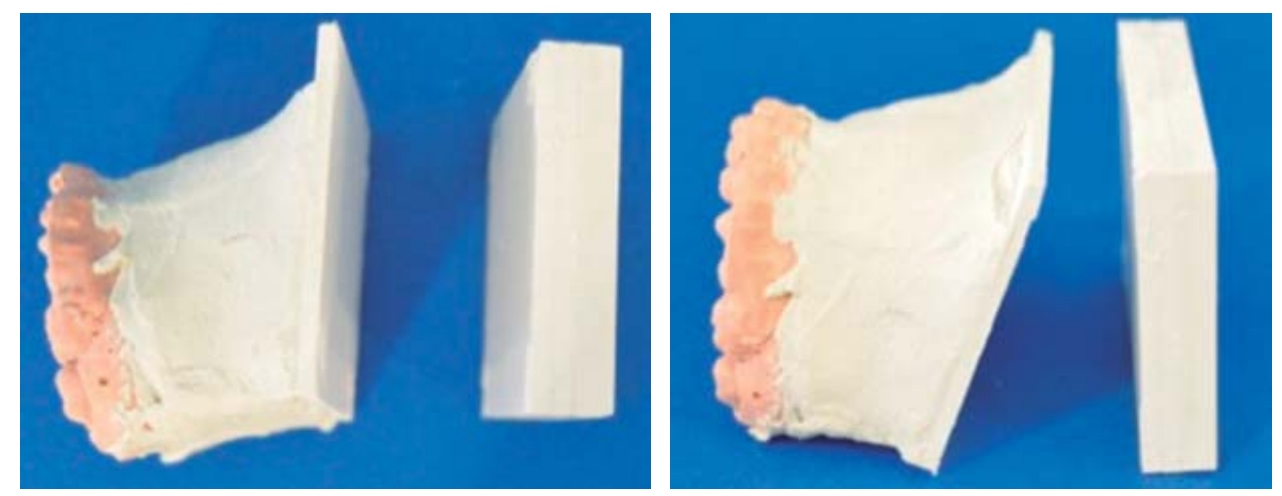

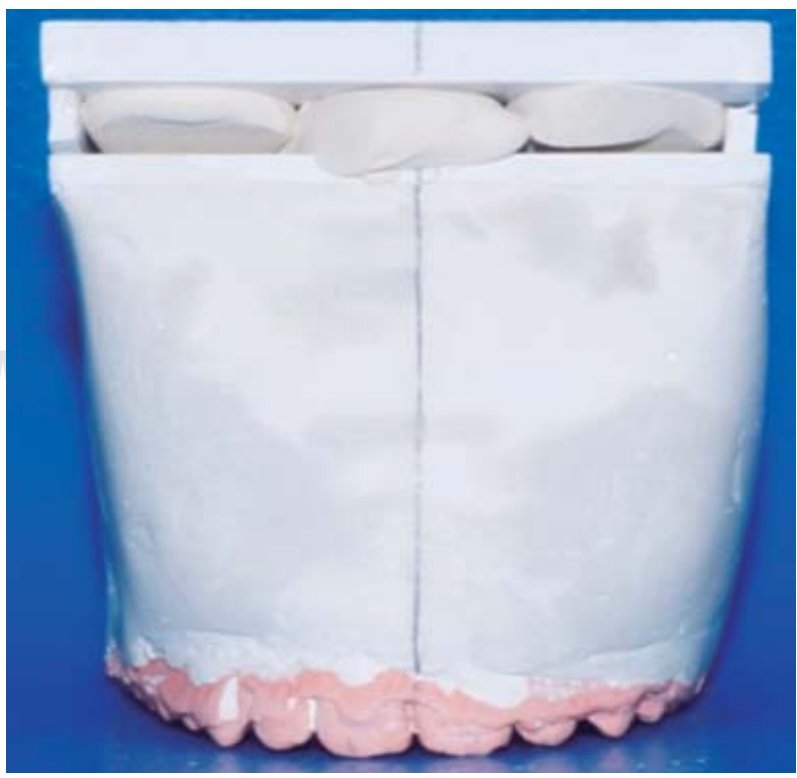

Figura 10:

Se agrega plastilina para ejecutar los movimientos en la cirugía de modelos. 

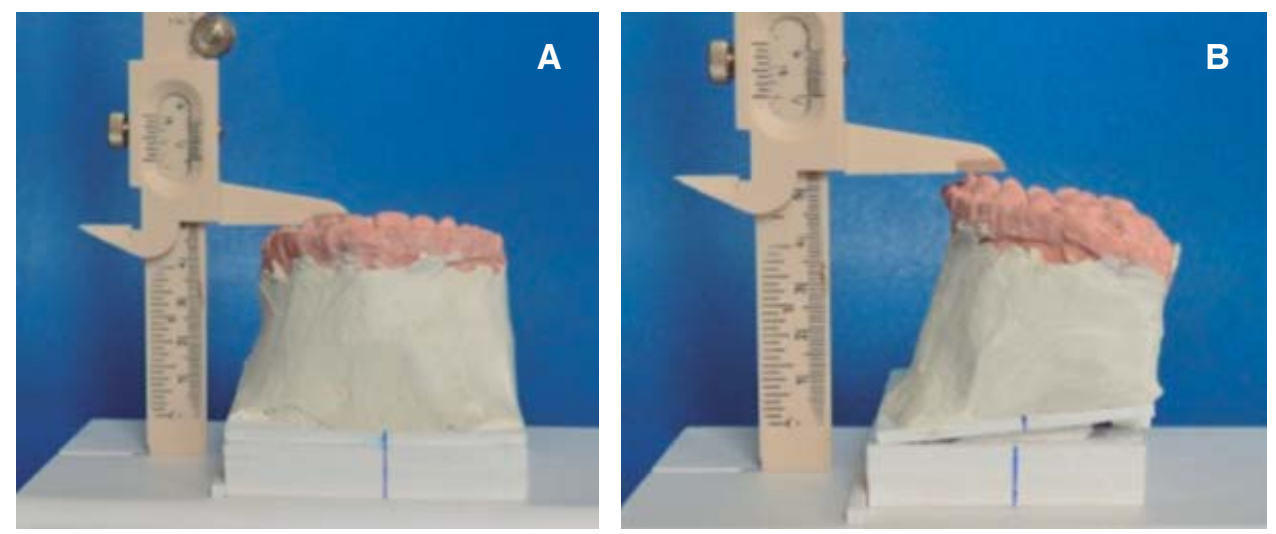

Figura 11:

Se corroboran las medidas

finales en la mesa de mediciones y en el articulador. A y B) Muestran el movimiento realizado en

la mesa de mediciones.

C) Modelo previo a la cirugía de modelos.

D) Movimiento realizado.
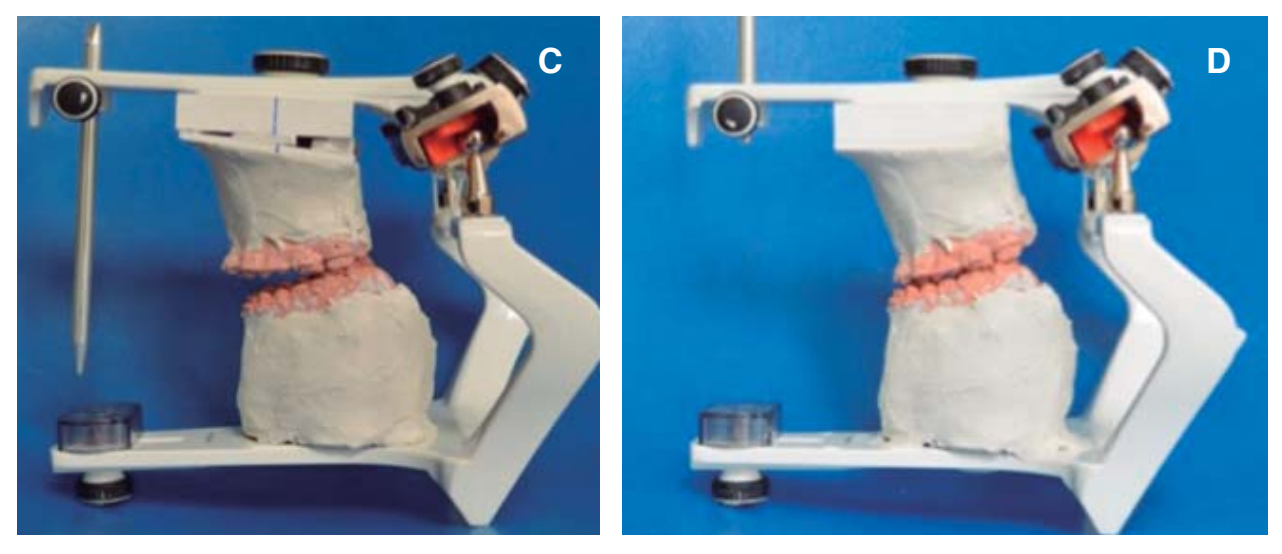
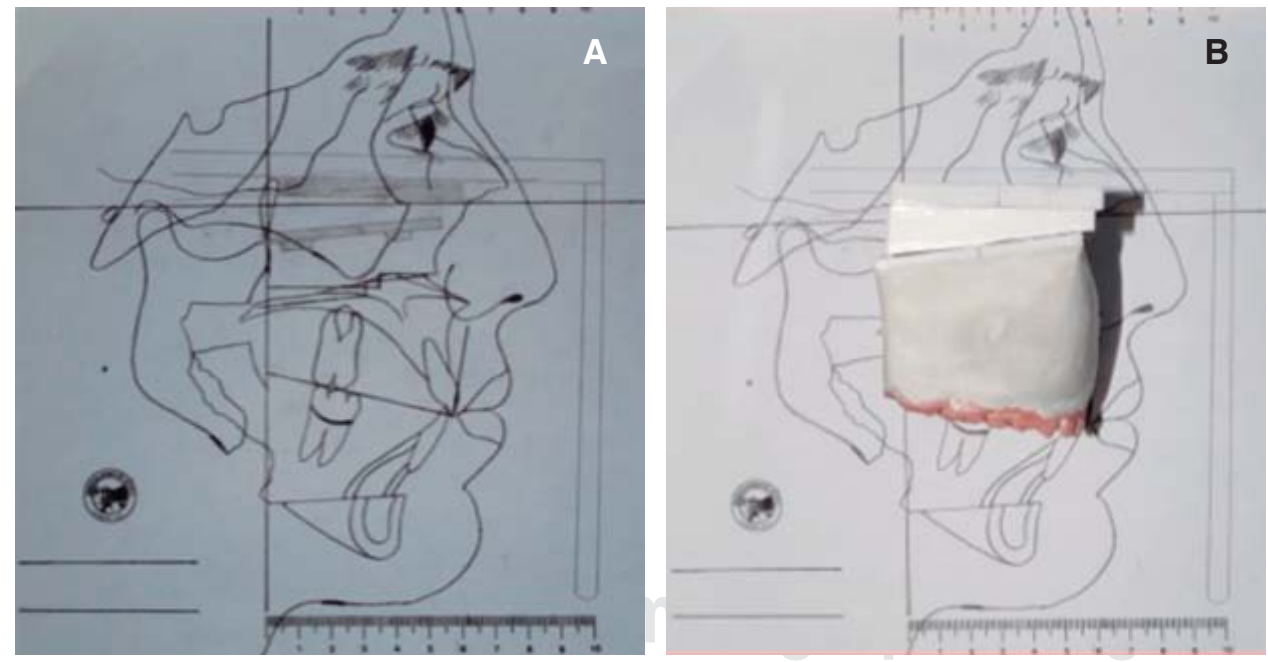

Figura 12:

Se corrobora el movimiento realizado en la predicción quirúrgica. A) Trazado de platinas y articulador. B) Superposición del modelo corroborando el movimiento de igual forma. para comprender el método virtual. $Y$ aun con este método, todavía está presente la dificultad técnica de su aplicación transoperatoria en el quirófano. ${ }^{10}$

La mayoría de los cirujanos siguen empleando la cirugía de modelos convencional como la presentada en el artículo. Este método convencional requiere ser reducido en tiempo y costo, sin sacrificar la exactitud del resultado. El método presentado demuestra ser un sistema sencillo que facilita al cirujano la planeación de la cirugía ortognática. Si bien es cierto que durante las maniobras pueden existir errores, estos siempre serán atribuidos al cirujano que realiza el procedimiento. 
Una de las grandes ventajas de utilizar este método es su rapidez, su precisión, y la limpieza de trabajo, aún en los casos de movimientos complejos y combinados.

Los grosores de las platinas facilitan el realizar movimientos de impactación o descenso, permitiendo aumentar o disminuir el espacio.

Por otro lado, está la ventaja de poder verificar el movimiento realizado sobre el mismo trazo de predicción quirúrgica, permitiendo confirmar la exactitud y efectividad del movimiento planeado con el realizado.

Una ventaja más de este método es la facilidad relativa de retiro o desprendimiento de las platinas pegadas de los segmentos intermedios utilizados para fijar el modelo después de realizar la maniobra. Esto permite fácilmente volver a realizar el procedimiento de cirugía de modelos desde el principio en caso de tener errores durante la manipulación de los modelos, y así corregir el error sin necesidad de repetir todo el procedimiento desde el inicio.

\section{CONCLUSIONES}

La cirugía de modelos es una parte imprescindible en la planeación de la cirugía ortognática; aunque los avances actuales en cirugía de modelos virtuales mediante la manipulación de imágenes del paciente en tercera dimensión facilitan y acortan el tiempo de este rubro, no se encuentra disponible en todos los países y los cirujanos no tienen acceso al mismo. Por otro lado el alto costo de este equipo hace inalcanzable para algunos cirujanos el contar con esta tecnología. La cirugía de modelos convencional es practicada por la mayoría de los cirujanos de este país, aunque existen en la actualidad mesas de mediciones y métodos para llevarla a cabo, su costo es elevado, difícil de transportar y en ocasiones difícilmente de entender, por lo que el método que presentamos tiene como ventajas su bajo costo, fácil manejo y entendimiento. La facilidad con la que se aplican las medidas obtenidas durante la predicción quirúrgica y el manejo amigable de las platinas disminuyen el margen de error de lo planeado en la predicción.

\section{BIBLIOGRAFÍA}

1. Epker BN, Stella JP, Fisch LC. Essentials of treatment planning. Dentofacial deformities integrated orthodontic and surgical correction. Vol. 4, 2a ed., St. Louis: Mosby: 1998.

2. Erickson KL, Bell WH, Goldsmith $\mathrm{DH}$. Analytical model surgery. In: Bell WH. Modern practice in orthognathic and reconstructive surgery. Editado por: Bell WH. Philadelphia: W. B. Saunders Company; 1992, pp. 155-216.

3. Chowdhary R, Walker F, Mankani N. Model surgery: a presurgical procedure for orthognatic surgeries-revisted. International Journal of Prosthodontics and Restorative Dentistry. 2011; 1 (1): 71-76.

4. Popat $\mathrm{H}$, Sandler PJ. A magnetic fixation and orientation system for orthognathic surgery planning models. Grand Rounds Maxillofacial Surgery. 2003; (3): 16-18.

5. Tsang AC, Lee AS, Li WL. Orthognathic model surgery with LEGO key-spacer. J Oral Maxillofac Surg. 2013; 71: 2154. E1-2154. E9.

6. Shehab MF, Barakast AA, AbdElbhany K, Mostafa Y. A novel design of a computer generated splint for vertical repositioning of the maxilla after Le Fort I osteotomy. Oral Surg Oral Med Oral Pathol Oral Radiol. 2013; 115: e16-e25.

7. Li B, Zhang L, Sun H, Yuan J, Shen SG, Wang X. A novel method of computer aided orthognathic surgery using individual CAD/CAM templates: a combination of osteotomy and repositioning guides. $\mathrm{Br}$ J Oral Maxillofac Surg. 2013; 51: e239-e244.

8. Zinser MJ, Sailer HF, Ritter L, Braumann B, Maegele M, Zoeller JE. A paradigm shift in orthognathic surgery? a comparison of navigation, computer-aided designed/computer-aided manufactured splints, and "classic" intermaxillary splints to surgical transfer of virtual orthognathic planning. J Oral Maxillofac Surg. 2013; 71: 2151.e1-2151.e21.

9. Kim BC, Lee CE, Park W, Kim MK, Zhengguo P, Yu HS et al. Clinical experiences of digital model surgery and the rapidprototyped wafer for maxillary orthognathic surgery. Oral Surg Oral Med Oral Pathol Oral Radiol Endod. 2011; 111: 278-285.

10. Krutoy J, Appleblat R. Two cases of maxillary malpositioning following maxillary and mandibular orthognathic surgery using CTguided virtual surgical planning. J Oral Maxillofac Surg. 2014; 72 (9): 138-139. 